\title{
Potential of Pine Biochar in Removal of Copper from Synthetic Waste Water
}

\author{
Rini Labanya*", P. C. Srivastava and S. P. Pachauri \\ Department of Soil Science, G.B. pant University of Agriculture \& Technology, \\ Pantnagar-263145, Uttarakhand, India \\ *Corresponding author
}

\section{A B S T R A C T}

\section{Keywords}

Biochar, Pine,

Temperature,

Copper, Adsorption, Desorption

Article Info

Accepted:

04 October 2020

Available Online:

10 November 2020
Mining, industrial processing, smelting and other industrial activities produce waste waters having toxic levels of $\mathrm{Cu}$ which have potential to contaminate natural water and soils. The present study focuses on the removal of $\mathrm{Cu}(\mathrm{II})$ from synthetic waste water containing $\mathrm{Cu}$ levels in the range of 15.9 to $143 \mathrm{mg} \mathrm{L}^{-1}$ onto Pine needle biochars prepared by pyrolysis at $300(\mathrm{P} 300)$ and $450^{\circ} \mathrm{C}(\mathrm{P} 450)$. The results indicated that $\mathrm{P} 450$ had many fold higher $\mathrm{Cu}$ removal capacity which could retain $98 \%$ of $\mathrm{Cu}$ present in wastewater containing nearly $50 \mathrm{mg} \mathrm{Cu} / \mathrm{l}$. The sorption-desorption data of $\mathrm{Cu}$ onto P300 and P450 conformed best to Langmuir isotherm as compared to Freundlich adsorption model. Adsorption maxima for $\mathrm{Cu}$ sorption of P300 and P450 were 1068.5 and $3516.0 \mathrm{mg} \mathrm{kg}^{-1}$, respectively. The values of constant (k) related to bonding energy P300 and P450 were 0.094 and $0.741 \mathrm{~kg} \mathrm{mg}^{-1}$, respectively. Hysteresis index calculated from Freundlich isotherms $\left(\mathrm{n}_{\text {des. }} / \mathrm{n}_{\text {ads. }}\right.$ ) were 37.3 and 299.5 for P300 and P450, respectively which clearly indicated an irreversible binding of $\mathrm{Cu}$ onto pine biochar which might work as a potential cheap adsorbent for remediation of $\mathrm{Cu}$ loaded toxic wastewaters.

\section{Introduction}

Heavy metals have been introduced into the environment as a result of industrial production, energy utilization, mining, and the application of pesticides and fertilizers (Ihsanullah et al., 2016; Sankhla et al., 2016; Siddiqui and Pandey, 2019). Copper (Cu II) is a potential toxicant at high doses (Tchounwou et al., 2012). Copper is one of the main waste generated from electroplating industries. According to Environmental Protection Agency (EPA) standards, the tolerance limit of $\mathrm{Cu}$ fixed for effluent discharge is $3 \mathrm{mg} \mathrm{L}^{-1}$
(EPA, 1993a). According to the Bureau of Indian Standards (BIS), the desirable concentration limit of $\mathrm{Cu}$ in drinking water is $0.05 \mathrm{mg} \mathrm{L}^{-1}$ and in the absence of alternate source the permissible limit is $1.5 \mathrm{mg} / \mathrm{L}$ (EPA, 1993b; BIS, 1991). Currently, the treatment strategies for attenuation of heavy metals mainly include chemical precipitation, ionic exchange, reverse osmosis and adsorption. Among these methods, the cheapest and the most effective methods are based on adsorption (sorption) processes occurring on the natural or synthetic adsorbents (Chen et al., 2011; Zhang et al., 
2014, 2017; Liu et al., 2017). Among different adsorbents (sorbents), biochars and other carbon adsorbents belong to the most perspective materials (Ahmad et al., 2014; Mohan and Pitmann 2006; Gupta and Nayak 2012; Wang et al., 2018). The widespread use of adsorbents has been limited by the lack of environment friendly and economical adsorbents (Park et al., 2015).

Biochar is a solid material produced during a process known as pyrolysis from the thermoconversion (slow, intermediate, and fast pyrolysis or gasification) of biomass under little or no oxygen which can also be used in soils as an amendment (Gaskin et al., 2008; Lehmann and Joseph 2009). Biochar can be produced from a range of feedstock, including forest and agriculture residues, such as straw, nut shells, rice hulls, wood chips/pellets, tree bark, bioenergy crops (willows, miscanthus, and switchgrass), forest residues (sawdust, grain crops, and nut shells), organic waste (green yard waste and animal manure), agricultural waste, kitchen waste, and sewage sludge, algae etc. and thus, has varying nutrient contents. The incomplete carbonisation of the biomass during the pyrolysis process changes the properties of the feedstock, resulting in the biochar with a porous structure, high surface area, high $\mathrm{pH}$, active functional groups and a graphite-like aromatic structure (Keiluweit et al., 2010; Manyà 2012; Ronsse et al., 2013; Xin et al., 2015). These properties result in high adsorption capacities of biochar for heavy metals (Keiluweit et al., 2010; Beesley et al., 2011; Inyang et al., 2015). As a complex carbon-rich substance, biochar adsorption mechanism of heavy metals in aqueous solution is very diverse, its surface oxygencontaining functional groups and binding sites can easily make complexation or ion exchange with heavy metal ions; in addition to that, some insoluble inorganic salt (form in the process of preparation of biochar) could co-precipitate with heavy metal ions on the surface. Biochar has been also described as a possible tool for soil fertility improvement, potential toxic element adsorption, and climate change mitigation. Namgay et al., (2010) reported that biochar application decreased the concentration of $\mathrm{As}, \mathrm{Cd}$, and $\mathrm{Cu}$ in maize shoots, depending on the amount of biochar addition, soil $\mathrm{pH}$, and ability of metal to adsorb on Biochar. Chen et al., (2008) assessed that pine-needle derived biochar was effective in removing nitrobenzene, naphthalene and m-dinitrobenzene from water. Previous studies have also demonstrated that the raw materials substantially affect the physicochemical properties and heavy metal adsorption capacity of biochar; therefore, choosing an appropriate feedstock is critical for the development of an efficient biochar (Suman et al., 2017; Zahedifar, 2017).

The disposal of enormous amounts of fallen pine (Pinus roxburghii) needles, usually found as waste biomass in coniferous forests is a challenge faced by local people as well as natural resource managers. Moreover, it plays a pivotal role in causing devastating forest fire due its high resin content. Extremely slow decomposition rate of pine needle also makes its disposal tough. Therefore, we tested the efficacy of the biochar produced from pine needle to remediate synthetic waste water containing high levels of $\mathrm{Cu}$ (II) to reduce heavy metal contamination of soil and water bodies. The specific objectives of this study were to investigate $\mathrm{Cu}$ removal capacity of Pine Biochar and to examine adsorption and desorption characteristics of pine biochar for $\mathrm{Cu}$ (II).

\section{Materials and Methods}

Pine needles were collected from International Guest House of G. B. Pant University of Agriculture and Technology, 
Pantnagar, Uttarakhand. These residues were dried to remove the moisture content in the biomass. The dried materials were chopped into small pieces to make them ready for the biochar preparation. Thereafter, these materials were incinerated in the muffle furnace at controlled temperature of 300 and $450^{\circ} \mathrm{C}$ under limited oxygen supply. The charred materials obtained after the pyrolysis were crushed in pestle and mortal to make them fine and homogenous powder-like material. Crushed samples were passed through $0.5 \mathrm{~mm}$ sieve and stored in plastic containers (labeled as PB300 and PB 450) for subsequent analysis and use.

Pine biochars (P300 and P450) were analyzed for elemental composition using $\mathrm{CHN}$ elemental analyzer. The equilibrium $\mathrm{pH}$ and specific electrical conductivity were also determined in 1:10 biochar: water suspensions using $\mathrm{pH}$ meter and electrical conductivity meter.

\section{Adsorption-desorption experiments}

Adsorption studies were carried out by equilibrating $0.5 \mathrm{~g}$ of biochar (P300 and $\mathrm{P} 450)$ in duplicate with different concentrations of $\mathrm{Cu}$ (II) $(0,2,4,6,8,10,12$, $14,16,18 \mathrm{ml}$ of stock solution containing $0.156 \mathrm{~g}$ of $\mathrm{CuSO}_{4} .5 \mathrm{H}_{2} \mathrm{O}$ in $250 \mathrm{~mL}$ in centrifuge tubes. A background solution of 2 $\mathrm{mL} 0.1 \mathrm{~N} \mathrm{NaNO}_{3}$ was added initially in each tube and the final volume was made up to 20 $\mathrm{ml}$ by distilled water. The tubes were then shaken on an orbital shaker at room temperature $\left(25 \pm 0.5^{\circ} \mathrm{C}\right)$ at $180 \mathrm{rpm}$ for $48 \mathrm{~h}$. After $48 \mathrm{~h}$, the solid and liquid phases were separated by centrifugation at $8000 \mathrm{rpm}$ for $10 \mathrm{~min}$ and then the supernatant was filtered with a $0.45-\mu \mathrm{m}$ filter and stored in plastic vials for $\mathrm{Cu}$ determination by AAS (GBCAvanta M). The percent removal of $\mathrm{Cu}$ (II) was calculated for different initial concentrations of $\mathrm{Cu}(\mathrm{II})$.
Percent Removal $(\%)=\frac{\text { Cu conc. in equil. soln. }(\mathrm{mg} / \mathrm{L})}{\text { Initial conc. of } \mathrm{Cu} \text { in soln. }(\mathrm{mg} / \mathrm{L})} \times 100$

The amount of $\mathrm{Cu}$ (II) adsorbed by pine biochar $\left(\mathrm{q}_{\text {ads. }}\right)$ was calculated as:

$\mathrm{q}_{\text {ads. }}=$

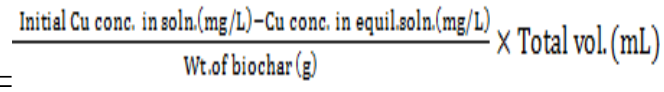

After adsorption, pine biochar samples subjected to $\mathrm{Cu}$ (II) adsorption with the highest $\mathrm{Cu}$ (II) concentration were dispersed in $20 \mathrm{~mL}$ water containing $2 \mathrm{~mL}$ of background electrolyte $\left.(0.1 \mathrm{M} \mathrm{NaNO})_{3}\right)$ was again equilibrated for $48 \mathrm{~h}$ on an orbital shaker, centrifuged and filtered to collect the supernatant for $\mathrm{Cu}$ (II) estimation as described in the preceding paragraph. The process was repeated five times.

After each desorption, the amount of $\mathrm{Cu}$ remaining adsorbed on biochar ( $\mathrm{q}$ remaining ads.) was calculated as:

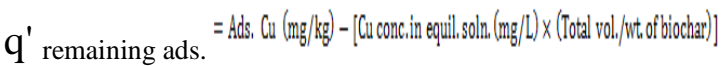

The experimental data on adsorptiondesorption of $\mathrm{Cu}$ (II) onto P300 and P450 were fitted to the following Freundlich and Langmuir models (Foo and Hameed, 2010) :

\section{Freundlich model}

$$
\begin{aligned}
& \mathrm{q}_{\text {ads. }}=\mathrm{K}_{\mathrm{F}} \mathrm{C}_{\mathrm{e}}{ }^{1 / \mathrm{n}} \\
& \mathrm{q}^{\prime} \text { remaining ads. }=\mathrm{K}_{\mathrm{F}}, \mathrm{C}_{\mathrm{e}},{ }^{1 / \mathrm{n}},
\end{aligned}
$$

\section{Langmuir model}

$\mathrm{q}_{\text {ads. }}=\mathrm{q}_{\max } \mathrm{kCe} /(1+\mathrm{b} \mathrm{Ce})$

q' remaining ads.= q' max k' Ce'/(1+ b' Ce')

Where, $\mathrm{q}$ ads. and $\mathrm{Ce}$ indicate the amount of $\mathrm{Cu}$ (II) sorbed by biochar and concentration of $\mathrm{Cu}$ (II) in equilibrium solution in 
adsorption studies, respectively. The quantities, q' remaining ads and Ce' depict the amount of $\mathrm{Cu}$ (II) remaining sorbed on biochar after desorption and desorbed concentration of $\mathrm{Cu}$ (II) in equilibrium solution, respectively. The values of $K_{F}, 1 / n$, $\mathrm{K}_{\mathrm{F}}$ and $1 / \mathrm{n}$ ' are Freundlich constants for adsorption and desorption processes, respectively. The values of $\mathrm{q}$ max., $\mathrm{k}, \mathrm{q}_{\text {max }}, \mathrm{k}$ ' indicate the adsorption/desorption maxima and constants related to bonding energy terms for Langmuir adsorption-desorption models, respectively.

The suitability of the model fitting was assessed on the basis of coefficient of determination $\left(\mathrm{R}^{2}\right.$ value $)$.

\section{Results and Discussion}

\section{General Properties of Pine biochar}

The properties of pine biochar shown in Table 1 clearly indicated that with the increase in pyrolysis temperature, there are decrease in $\mathrm{C} \%$ and $\mathrm{H} \%$ and a slight increase in $\mathrm{O} \%$. The value of $\mathrm{H} / \mathrm{C}$ ratio is an indicator of aromaticity of biochar. The analysis showed that this ratio decreased with increase in temperature; indicating that there was higher aromaticity (double or triple bonds) in P450 as compared to $\mathrm{P} 300$. This ratio also seems to be a perfect index for predicting the sorption of hydrophobic organic contaminants (HOCs) onto biochars. A linear relationship between $\mathrm{H} / \mathrm{C}$ and the Freundlich fitting parameters was reporteted by Chen et al.(2008). The value of $\mathrm{O} / \mathrm{C}$ ratio is a measure of polarity. Higher ratio indicated presence of more polar functional groups, which could take part in adsorption of $\mathrm{Cu}$ (II).

With an increase in pyrolysis temperature, there was an enrichment of basic cations in the ashes, which could be associated with oxides, hydroxides and carbonates of alkali and alkaline earth metals (Yuan et al.2011; Ding et al.2014) along with a reduction in the concentration of acidic surface functional groups (Al-Wabel et al.2013); which might be the plausible reason for higher $\mathrm{pH}$ in pine needle biochar produced at higher temperature $\left(450^{\circ} \mathrm{C}\right)$. Above $300^{\circ} \mathrm{C}$, alkali salts also likely to separate from the organic matrix, increasing the $\mathrm{pH}$ of the biochar.

The EC of pine biochars also increased with pyrolysis temperature due to loss of volatile matters, resulting in concentration of oxides of these elements in the ash fraction (Cantrell et al., 2012). Higher mineral ash in $\mathrm{P} 450$ could be the probable cause of higher electrical conductivity due to high $\mathrm{K}$ content (Joseph et al., 2014).

\section{Percent removal of $\mathrm{Cu}$ (II) from synthetic waste water}

The data on percent removal of $\mathrm{Cu}$ (II) affected by P300 and P450 from synthetic waste water are depicted in Fig. 1 which clearly indicates that P450 was more effective in removal of $\mathrm{Cu}$ (II) from synthetic waste water compared to P300. For an initial concentration of $\mathrm{Cu}$ (II) around $47.7 \mathrm{mg} / \mathrm{L}$, $\mathrm{P} 450$ removed 98.1 percent of $\mathrm{Cu}$ from waste water while only $41.3 \%$ percent could be sorbed by $\mathrm{P} 300$. Considering $1.5 \mathrm{mg} \mathrm{Cu}$ (II) as the tolerance limit for inland surface water subject to pollution (Class C) as per Indian standards (IS, 1982), P450 might serve as a cheap and effective sorbent for the treatment electroplating waste water containing higher levels of $\mathrm{Cu}$ (II).

\section{Adsorption-desorption isotherm of $\mathrm{Cu}$ (II)}

The adsorption-desorption isotherms of $\mathrm{Cu}$ (II) onto P300 and $\mathrm{P} 450$ at $25^{\circ} \mathrm{C}$ are depicted in Fig.2. In general adsorption isotherms of $\mathrm{Cu}(\mathrm{II})$ onto P300 and P450 were L-type indicating a decrease in adsorption energy 
with increasing occupancy of the available adsorption sites. Compared to P300 there was an abrupt initial increase in sorbed amount of $\mathrm{Cu}$ (II) onto $\mathrm{P} 450$ indicating higher specificity of this sorbent for $\mathrm{Cu}$ (II) and the isotherm showed saturation or flattening of the adsorption curve at more than threefold higher adsorption capacity. The desorption isotherms of $\mathrm{Cu}$ (II) for P300 and P450 were limited in a very narrow range of desorbed $\mathrm{Cu}$
(II) in the equilibrium solution indicating very low reversibility of adsorbed $\mathrm{Cu}$ (II). A wider gap between adsorption and desorption isotherms of $\mathrm{Cu}$ (II) in the case of P450 indicated very limited desorption of $\mathrm{Cu}(\mathrm{II})$ from P450. The values of cumulative desorption of $\mathrm{Cu}$ (II) as percentage of adsorbed amount in five cycles of desorption were 8.29 and 1.02 percent for P300 and $\mathrm{P} 450$, respectively.

Table.1 General properties of pine biochars

\begin{tabular}{|c|c|c|}
\hline Components & Pine 300 & Pine 450 \\
\hline $\mathrm{C}(\%)$ & 61.34 & 59.89 \\
\hline $\mathrm{H}(\%)$ & 4.30 & 3.75 \\
\hline $\mathrm{O}(\%)$ & 32.38 & 34.34 \\
\hline $\mathrm{N}(\%)$ & 1.82 & 1.86 \\
\hline $\mathrm{H} / \mathrm{C}$ & 0.84 & 0.75 \\
\hline $\mathrm{O} / \mathrm{C}$ & 0.39 & 0.43 \\
\hline $\mathrm{pH}(1: 10)$ & 6.17 & 6.57 \\
\hline E.C. $(\mu \mathrm{S} \mathrm{cm}-1)$ in $1: 10$ at & 69.51 & 215.83 \\
\hline $25 \circ \mathrm{c}$ & & \\
\hline
\end{tabular}

Table.2 Freundlich- and Langmuir- model odelconstants and coefficient of determination for adsorption-desorption of $\mathrm{Cu}$ (II) onto pine needle biochars (P300 and P450)

\begin{tabular}{|c|c|c|c|}
\hline Models & Constants & P300 & P450 \\
\hline \multirow{3}{*}{$\begin{array}{l}\text { Freundlich adsorption } \\
\text { model }\end{array}$} & $\mathrm{KF}\left(\mathrm{mg} \mathrm{kg}^{-1}\right)$ & 283.0 & 1519.2 \\
\hline & $1 / \mathrm{n}$ & 0.2757 & 0.2396 \\
\hline & R2-value & $0.930 * *$ & $0.934 * *$ \\
\hline \multirow{4}{*}{$\begin{array}{l}\text { Freundlich desorption } \\
\text { model }\end{array}$} & $\mathrm{KF}^{\prime}\left(\mathrm{mg} \mathrm{kg}^{-1}\right)$ & 877.4 & 3328.1 \\
\hline & $1 / \mathrm{n}$ & 0.0074 & 0.0008 \\
\hline & R2-value & $0.796^{*}$ & $0.964 * *$ \\
\hline & H-index $\left(n^{\prime} n^{-1}\right)$ & 37.3 & 299.5 \\
\hline \multirow{3}{*}{$\begin{array}{l}\text { Langmuir adsorption } \\
\text { model }\end{array}$} & $\mathrm{q} \max \left(\mathrm{mg} \mathrm{kg}^{-1}\right)$ & 1068.5 & 3516.0 \\
\hline & $\mathrm{k}\left(\mathrm{L} \mathrm{kg}^{-1}\right)$ & 0.094 & 0.741 \\
\hline & R2-value & $0.984 * *$ & $0.996 * *$ \\
\hline \multirow{3}{*}{$\begin{array}{l}\text { Langmuir desorption } \\
\text { model }\end{array}$} & 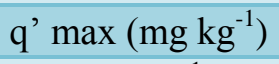 & 893.6 & 3329.6 \\
\hline & $\mathrm{k}^{\prime}\left(\mathrm{L} \mathrm{kg}^{-1}\right)$ & 149.0 & 5662.5 \\
\hline & R2-value & $0.999 * *$ & $0.999 * *$ \\
\hline
\end{tabular}

* Significant at $\mathrm{p} \leq 0.05, * *$ Significant at $\mathrm{p} \leq 0.01$ 
Fig.1 Percent removal of $\mathrm{Cu}$ (II) from synthetic waste water by pine biochars (P300 and P450)

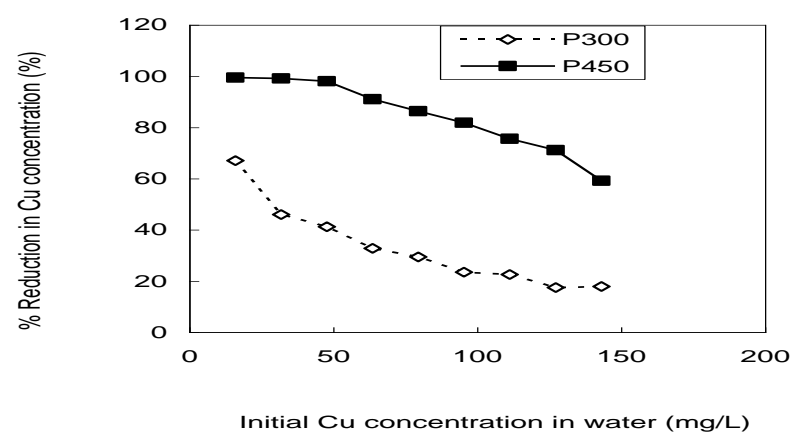

Fig.2 Adsorption-desorption isotherms of $\mathrm{Cu}$ (II) onto pine biochars (P300 and P450)

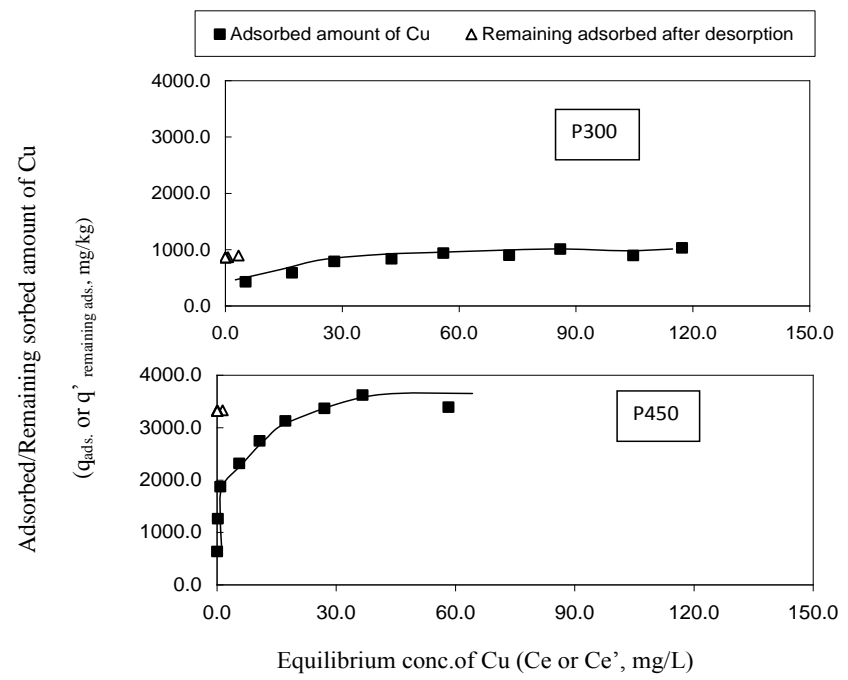

Fig.3 Freundlich (a) and Langmuir (b) adsorption-desorption isotherms of $\mathrm{Cu}$ (II) onto pine biochars (P300 and P450)
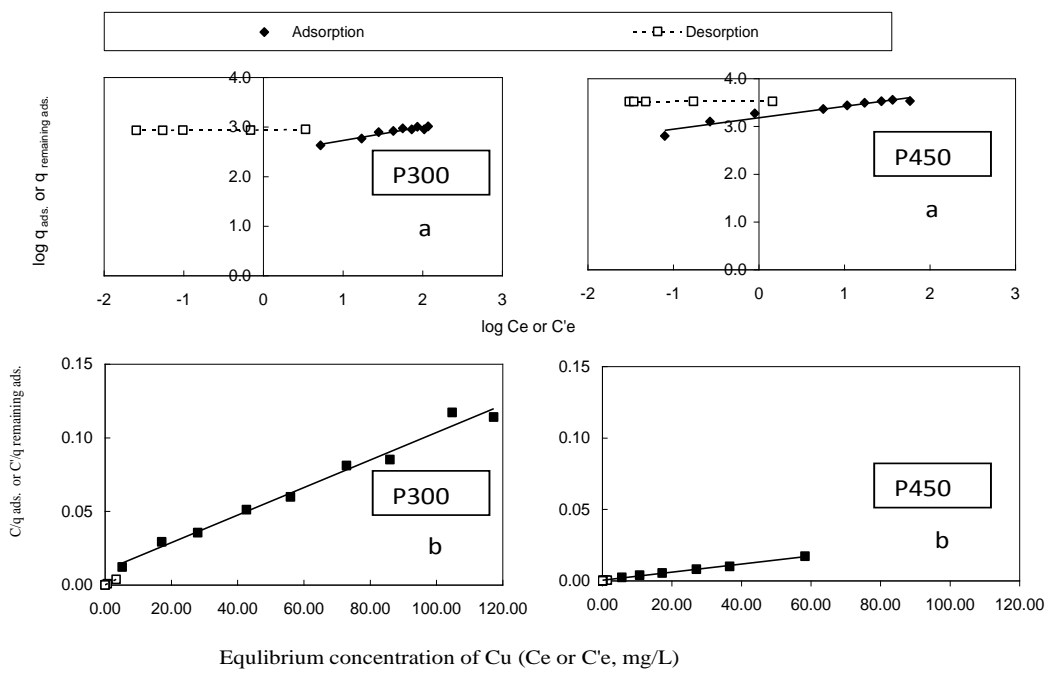
The computed values of different constants pertaining to Freundlich and Langmuir models along with the coefficient of determination $\left(\mathrm{R}^{2}\right)$ are presented in Table 2. A close perusal of the values indicated that though both the models could successfully account the adsorption-desorption of $\mathrm{Cu}$ (II) onto P300 and P450 however, Langmuir model was the best as this model yielded the highest $R^{2}$ values (all significant at $\mathrm{p} \leq 0.01$ ). The computed value of adsorption maximum (q max.) and desorption maximum (q'max.) for P450 were more than threefold higher as compared to that of P300. Similarly, the values of constant related to the bonding energy ( $k$ and k') were also higher for P450 as compared to P300 indicating very strong bonding of sorbed $\mathrm{Cu}$ (II) onto P450. Hysteresis index (H-index) values calculated from slopes of Freundlich isotherms were 37.3 and 299.5 for P300 and P450, respectively indicating irreversible retention of $\mathrm{Cu}$ (II) by pine biochars and the effect was more pronounced in $\mathrm{P} 450$ which could be ascribed to more condensed aromatic structure of P450 (Fig. 3).

These findings can be explained by an increase in porosity and surface areas of biochar produced by high temperature pyrolysis (P450), which ultimately increase the adsorption of metals (Chen et al., 2014). It is frequently suggested that high pyrolysis temperatures lead to increased porosity and surface area compared with biochar prepared at low temperature. High incineration temperature also increases the concentration of minerals $(\mathrm{K}, \mathrm{Ca}, \mathrm{Mg}$ and $\mathrm{P})$ on the surface of sorbents that could be used for ion exchange with heavy metals (Chen et al., 2014; Hossain et al., 2011; Subedi et al., 2016). Chen et al., (2011) revealed that biochar from corn straw $\left(600{ }^{\circ} \mathrm{C}\right)$ and wood biochar $\left(450^{\circ} \mathrm{C}\right)$ had high heavy metal sorption efficiency. The removal of $\mathrm{Cu}$ was $56.6 \%$ for wood biochar and $98.2 \%$ for biochar from corn straw. On the other hand, Komkiene and Baltrenaite (2015) observed that heavy metal ions removal efficiency was about $35-37 \%$ on silver birch biochar. Karami et al., (2011) showed that the addition of oak derived biochar in the amount of $20 \%(v / v)$ to the soil reduced the $\mathrm{Cu}$ sorption by about 69\%. On the other hand, Xu and Zhao (2013) proved that biochar from straws of canola and peanut increased the $\mathrm{Cu}$ sorption capacity of three soils (Oxisol and Utisol) by about $54.2 \%$ and $102.1 \%$, when 3 and $5 \%$ of biochar were added. Considering these works, it could be anticipated that above variations in results might result from the differences in nature of the feedstock and pyrolysis temperature.

In conclusion the biochar derived from the pyrolysis of pine needles at 300 and $450^{\circ} \mathrm{C}$ varied in general properties as well as $\mathrm{Cu}$ (II) sorption characteristics. Pine biochar prepared by pyrolysis at $450^{\circ} \mathrm{C}$ had higher sorption capacity for $\mathrm{Cu}$ (II) as compared to pine biochar pyrolyzed at $300^{\circ} \mathrm{C}$. Adsorptiondesorption data of $\mathrm{Cu}$ (II) onto pine biochar closely conformed to Langmuir model. Pine biochar prepared by pyrolysis at $450^{\circ} \mathrm{C}$ can serve as a potential cost effective sorbent for the treatment of $\mathrm{Cu}$ (II) waste water generated from electroplating industries.

\section{References}

Ahmad, M., Rajapaksha, A.U., Lim, J.E., Zhang, M., Bolan, N., Mohan, D., Vithanage, M., Lee, S.S. and Ok, Y.S. (2014). Biochar as a sorbent for contaminant management in soil and water: A review. Chemosphere, 99: 1933.

Al-Wabel, M.I., Al-Omran, E., El-Naggar, A.H., Nadeem, M. and Usman, A.R. (2013) Pyrolysis temperature induced changes in characteristic and chemical composition of biochar produced from 
conocarpus wastes. Bioresour Technol 131:374-379.

Anonymous (1982). Indian standard tolerance limits for inland surface, waters subject to pollution, IS:2296-1982. Indian Standards Institution, New Delhi, India.

Beesley, L., Moreno-Jiménez, E., GomezEyles and J.L. (2011) A review of biochars' potential role in the remediation, revegetation and restoration of contaminated soils. Environ Pollut 159:3269-3282.

Cantrell, K.B., Hunt, P.G. and Uchimiya, M. (2012) Impact of pyrolysis temperature and manure source on physicochemical characteristics of biochar. Bioresource Technology 107: 419-428.

Chen, B.L., Zhou, D.D. and Zhu, L.J. (2008). "Transitional adsorption and partition of nonpolar and polar aromatic contaminants by biochars of pine needles with different pyrolytic temperatures," Environmental Science and Technology. 42(14):5137-5143.

Chen, X., Chen, G., Chen, L., Chen, Y., Lehmann, J., McBride, M.B. and Hay, A.G. (2011) Adsorption of copper and zinc by biochars produced from pyrolysis of hardwood and corn straw in aqueous solution. Bioresour Technol 102:8877-8884

Chen, T. Yaxin, Z., Hongtao, W., Wenjing, Lu., Zeyu, Z., Yuancheng, Z. and Lulu. (2014). Influence of Pyrolysis Temperature on Characteristics and Heavy Metal Adsorptive Performance of Biochar Derived from Municipal Sewage Technol. 164, 47-54.

Ding, W., Dong, X., Ime, I.M., Gao, B. and Ma, L.Q. (2014) Pyrolytic temperatures impact lead sorption mechanisms by bagasse biochars. Chemosphere 105:68-74.

EPA (1993a). Environment (Protection) Third
Amendment Rules, 1993 on water quality - (i) mine discharge / workshop / colony effluents, vide notification no. G.S.R 801 (E) dated 31.12.1993.

EPA (1993b).Environment (Protection) Third Amendment Rules, 1993 on water quality - (ii) ground water, vide notification no. BIS 105000:1991.

Foo, K.Y. and Hameed, B.H. (2010) Insights into the modeling of adsorption isotherm systems. Chem Eng J 156:210.

Gaskin, J. W., Steiner, C., Harris, K., Das, K. C. and Bibens, B. (2008) Effect of lowtemperature pyrolysis conditions on biochar for agricultural use. Transactions of the ASABE 51, 20612069.

Gupta VK, Nayak A (2012) Cadmium removal and recovery from aqueous solutions by novel adsorbents prepared from orange peel and $\mathrm{Fe}_{2} \mathrm{O}_{3}$ nanoparticles. Chem Eng $J$ 180:81-90

Hossain, M. K., Strezov, V., Chan, K., Ziolkowski, A. and Nelson, P. F.(2011). Influence of Pyrolysis Temperature on Production and Nutrient Properties of Wastewater Sludge Biochar. J. Environ. Manage. 92(1), 223-228.

Ihsanullah, A., A.,Al-Amer, A.M., Lauoi, T., Al-Marrie, M.J.,Naseer, M.S., Khraisheh, M. and Atieh, M.A. (2016). Heavy metal removal from aqueous solution by advanced carbon nanotubes: Critical review of adsorption applications. Sep. Purif. Technol. 157, 141-161.

Inyang, M.I., Gao, B. and Yao, Y. (2015) A review of biochar as a low-cost adsorbent for aqueous heavy metal removal. Crit Rev Environ Sci Technol:02-08.

Joseph, S.D., Downie, A. and Munroe, P. (2014) Biochar for carbon 
sequestration, reduction of greenhouse gas emissions and enhancement of soil fertility: a review of the materials science. Proceedings of the Australian Sydney. pp. 130-133.

Karami, N., Clemente, R., Moreno-Jimenez, E., Lepp, N.W. and Beesley, L. (2011) Efiiciency of green waste compost and biochar soil amendments for reducing lead and copper mobility and uptake to ryegrass. J Hazard Mater 191:41-48

Keiluweit, M., Nico, P.S., Johnson, M. and Kleber, M. (2010) Dynamic molecular structure of plant biomass-derived black carbon (biochar). Environ Sci Technol 44:1247-1253.

Komkiene, J. and Baltrenaite, E. (2015) Biochar as adsorbent for removal of heavy metal ions [Cadmium(II), Copper(II), Lead(II), Zinc(II)] from aqueous phase. Int $J$ Environ Sci Technol 13:471-482.

Lehmann, J. and Joseph, S. (2009) Biochar for environmental management: an introduction. In Biochar for Environmental Management: Science and Technology. Eds. J Lehmann and S Joseph. pp 1-12. Earthscan, London, UK.

Liu, C., Liu, F., Ravnskov, S., Rubæk, G.H., Sun, Z., Andersen, M.N., (2017). Impact of wood biochar and its interactions with mycorrhizal fungi, phosphorus fertilization and irrigation strategies on potato growth. J. Agron. Crop Sci. 203, 1385-1427.

Manyà, J.J. (2012) Pyrolysis for biochar purposes: a review to establish current knowledge gaps and research needs. Environ Sci Technol 46:7939-7954.

Mohan, D., Pitman, C.U. Jr, Steele, P.H. (2006) Pyrolysis of wood/biomass for bio-oil: a critical review. Energy Fuels 20:848-889.

Namgay, T., Singh, B., and Singh, B.P. (2010). Influence of biochar application to soil on the availability of $\mathrm{As}, \mathrm{Cd}, \mathrm{Cu}, \mathrm{Pb}$, and $\mathrm{Zn}$ to maize (Zea mays L.), Australian Journal of Soil Research, 48(6-7):638-647.

Park, J. H., Cho, J.S. ,Ok , Y.S., Kim, S.H., Heo , J.S., Delaune, R.D., Seo, D.C.(2015).Comparison of single and competitive metal adsorption by pepper stem biochar. Arch. Agron. Soil Sci. 62, 617-632.

Ronsse, F., van Hecke, S., Dickinson, D. and Prins, W. (2013) Production and characterization of slow pyrolysis biochar: influence of feedstock type and pyrolysis conditions. GCB Bioenergy 5:104-115

Sankhla, M. S., Kumari, M., Nandan, M., Kumar, R. and Agrawal, P. (2016).Heavy Metals Contamination in Water and their Hazardous Effect on Human Health-A Review. Int. J. Curr. Microbiol. App. Sci. 5, 759-766.

Siddiqui, E. and Pandey, J. (2019). Assessment of heavy metal pollution in water and surface sediment and evaluation of ecological risks associated with sediment contamination in the Ganga River: a basin-scale study. Environ Sci Pollut Res Int. 26, 10926-10940

Subedi, R., Taupe, N., Pelissetti, S., Petruzzelli, L., Bertora, C., Leahy, J.J. and Grignani, C. (2016). Greenhouse Gas Emissions and Soil Properties Following Amendment with ManureDerived Biochars: Influence of Pyrolysis Temperature and Feedstock Type. J. Environ. Manage. 166, 73-83.

Suman, S., Panwar, D. S. and Gautam, S. (2017). Surface morphology properties of biochars obtained from different biomass waste. Energy Sources, Part A: Recovery, Utilization, and Environmental Effects 1-6.

Tchouwnou, P.B., Yedjou, C.G., Patlolla, A.K., and Sutton, D. (2012). Heavy 
metal toxicity and the environment. EXS 101: 133-164.

Wang, S., Xu, Y., Namkha, N., and Wang, Z. (2018). Remediation of biochar on heavy metal polluted soils. IOP Conference Series Earth and Environmental Science 108(4):042113.

Xin, S., Yang, H. and Chen, Y. (2015) Chemical structure evolution of char during the pyrolysis of cellulose. $J$ Anal Appl Pyrolysis.

$\mathrm{Xu}, \mathrm{R}-\mathrm{k}$ and Zhao, A-Z .(2013) Effect of biochars on adsorption of $\mathrm{Cu}$ (II), $\mathrm{Pb}$ (II) and $\mathrm{Cd}(\mathrm{II})$ by three variable charge soils from southern China. Environ Sci Pollut Res 20:8491-8501.

Yuan J-H., Xu R-K. and Zhang, H. (2011) The forms of alkalis in the biochar produced from crop residues at different temperatures. Bioresour Technol 102:3488-3497.

Zahedifar, M. (2017). Sequential extraction of zinc in the soils of different land use types as influenced by wheat straw derived biochar. J. Geochem. Explor. 182, 22-31.

Zhang X, He L, Sarmah A, Lin K, Liu Y, Li J, Wang H (2014) Retention and release of diethyl phthalate in biocharamended vegetable garden soils. J Soils Sediments 14:1790-1799

Zhang, R-H., Li, Z-G., Liu, X-D., and Wang, B-C. (2017). Immobilization and bioavailability of heavy metals in greenhouse soils amended with rice straw-derived biochar. Ecological Engineering, 98.

\section{How to cite this article:}

Rini Labanya, P. C. Srivastava and Pachauri, S. P. 2020. Potential of Pine Biochar in Removal of Copper from Synthetic Waste Water. Int.J.Curr.Microbiol.App.Sci. 9(11): 185-194. doi: https://doi.org/10.20546/ijcmas.2020.911.022 